\title{
Algorithm development of structural variables for slope reinforcement of hydrotechnic structures with synthetic materials
}

\author{
Andrey Mikhasek ${ }^{1, *}$ Maxim Rodionov ${ }^{1}$, Vladimir Seliverstov ${ }^{1}$, and Yury Senitsky ${ }^{1}$ \\ ${ }^{1}$ Samara State Technical University, Institute of Architecture and Civil Engineering, \\ Molodogvardeyskaya str. 194, 443001 Samara, Russia
}

\begin{abstract}
The construction of hydrotechnic structures out of watercourse area is usually done with grass seeding above a vegetative soil layer. For stability of slope protection, during and after construction, it is suggested that vegetated soil is reinforced with cubic geosynthetic mats. To choose a geosynthetic material the algorithm is offered, taking into account conditions that provide resistance of vegetated soil layer, and depending on forces that act upon the slope and considering changes of material properties in course of time technological peculiarities of its placement.
\end{abstract}

\section{Introduction}

In the process of hydrotechnic structures construction with reinforced slopes we suggest to distinguish 3 vertical elements: a lower (underwater), a middle (in the area of variable level) and an upper one. Based on structural-technological analysis of the already existed bank protections and slope reinforcements of hydrotechnic structures and solutions involving modern materials [1-6] we come to the following construction solution (Fig. 1): the lower element - в виде банкет из rock mass, where a crest and a higher point of the slope are fastened with a quarry fill which sizes and mass are determined according to calculations of resistance to ice and wave impacts. The inner slope of the bank is protected with a breakstone filter of 20-40 мм and $20 \mathrm{~cm}$ thick, on which a geotextile layer with density $350 \mathrm{gr} / \mathrm{m}^{2}$ is placed, and a foundation of the existed slope is filled with sand drainage) $0.5 \mathrm{~m}$ thick to prevent suffusion carry-over. The lower side of the bank is constructed with sand backing. The middle one is a slope with filling $1: 2.5 \div 3$, which is fastened to concrete mats, placed on a geotextile layer. This solution is quite technological as well as economical and time-saving.

The construction of the upper element, which we recommend to construct up to the natural boundaries of a higher slope part is grass seeding on the vegetated soil layer with reinforcement of synthetic erosion-preventive material.

There are a lot of different types of geosynthetic materials which are produced in Europe, Asia region, Russia and can be used for slope protection of the upper element.

\footnotetext{
* Corresponding author: andremixas@mail.ru
} 
But nevertheless there is no method for structural variables, that's why algorithm development for choosing geosynthetic material for slope reinforcement of hydrotechnic structure is of great importance.

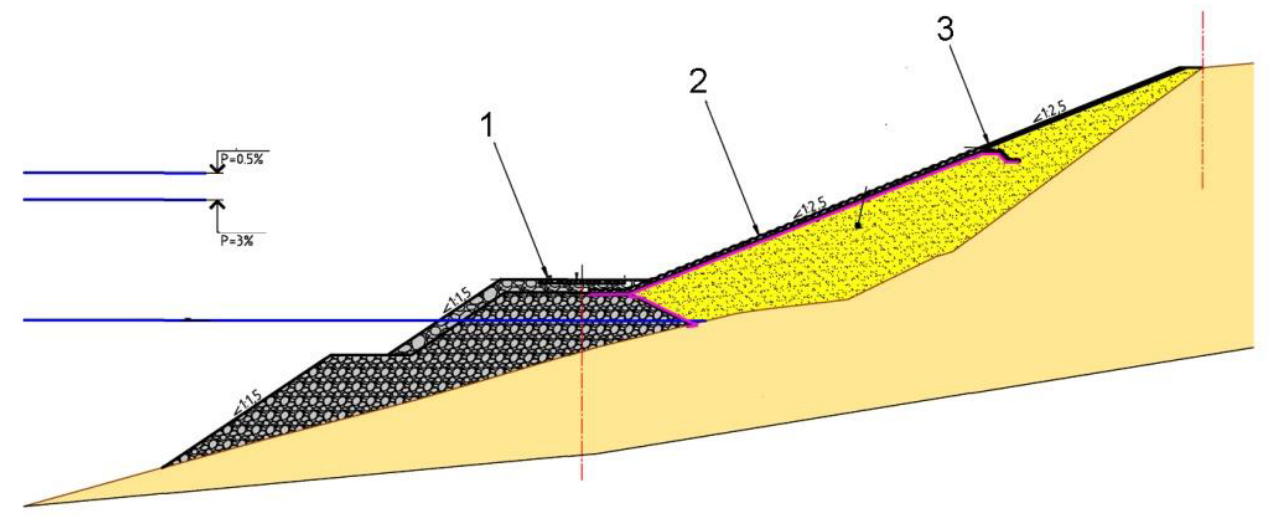

Fig. 1. Reinforcement option using composite and synthetic materials 1 - lower reinforcement element, 2 - middle, 3 - upper.

\section{Research}

The requirements for the material which is placed in the upper element of reinforcement are the following:

- slope protection from wind erosion;

- protection from water erosion.

These tasks are maintained by plurannual grass root system, planted along the slope. But from construction period up to strengthening of the root system additional protection is required, which can be achieved by adding a reinforcement layer made from geosynthetic materials.

It is recommended to use a cubic geosynthetic mat which allows to increase adhesion area with vegetated soil as well as surface resistance to rain and ice water. Considering the conditions of construction work and reinforcement slope stability it is recommended to place $5 \mathrm{~cm}$ vegetated soil layer just above and below the mat, and plurannual grass seeding - about $2 \mathrm{~cm}$ from the upper layer boundary.

As there is no method for choosing geosynthetic material, we offer to do it according stiffness properties. Calculated scheme for load determination is shown in (Fig. 1), calculated stiffness of surface reinforced material Fs is calculated [1]:

$$
\mathrm{F}_{\mathrm{s}}=\mathrm{L} \cdot\left(\mathrm{H} \cdot \gamma_{\mathrm{s}}+\mathrm{S}_{\mathrm{d}} \cdot \cos \beta\right) \cdot(\sin \beta-\operatorname{tg} \delta \cdot \cos \beta)
$$

L - actual slope lenght, $\mathrm{m}$;

$\mathrm{H}$ - thickness of geomat and vegetated soil layer, $\mathrm{m}$;

$\gamma_{\mathrm{s}}$ - calculated relative density of soil, $\mathrm{\kappa N} / \mathrm{m}^{3}$;

$\mathrm{S}_{\mathrm{d}}$ - calculated total load on the slope (including snow load), $\mathrm{KN} / \mathrm{m}^{2}$;

$\beta$ - slope angle, ${ }^{\circ}$;

$\delta$ - friction interaction angle «geomat - soil» (depends on internal friction soil angle and a type of reinforced material), ${ }^{\circ}$. 


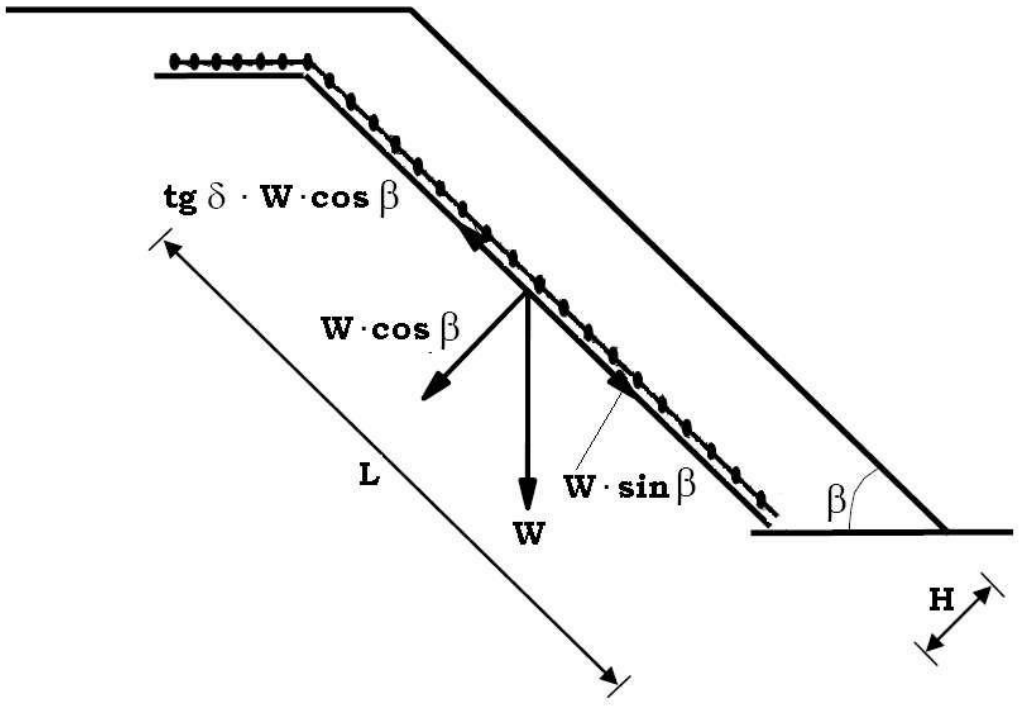

Fig. 2. Calculated scheme.

For the stability of slope surface the fulfillment of the condition is required:

$$
\mathrm{F}_{\mathrm{d}} \geq \mathrm{F}_{\mathrm{s}}
$$

$\mathrm{F}_{\mathrm{d}}$ - calculated (designed) hardness of reinforced material, estimated with a formula:

$$
F_{d}=F /\left(A_{1} \cdot A_{2} \cdot A_{3} \cdot A_{4} \cdot \gamma_{B}\right)
$$

$\mathrm{F}$ - short-term hardness of reinforced material (tensile strength);

$A_{1}$ - decreasing coefficient of long-lasting material stiffness, directly connected with material creep and structure durability $[8,9]$;

$\mathrm{A}_{2}$ - increasing coefficient of material in the course of handling, placement and soil compaction, depends on the type of geosynthetic material and soil type $[8,9]$;

$\mathrm{A}_{3}$ - decreasing coefficient of material stiffness if there are joints (for calculations $\mathrm{A}_{3}=$ 1.00 with the absence of joints towards load acting) $[8,9]$;

$\mathrm{A}_{4}$ - decreasing coefficient of material stiffness for outer effects resistance - resistance to microorganisms, X-rays, chemical environment, temperature change [8, 9];

$\gamma_{\mathrm{B}}$ - general reserve coefficient of geosynthetic material construction, is taken according to the recommendations [8].

Variables $A_{1}, A_{2}$, и $A_{4}$ for synthetic materials are provided by manufacturing plant and determined by the results of independent lab tests and must be certified.

Base on the formulae given above, a short-term material stiffness for surface reinforcement is estimated by the following way:

$$
F \geq L_{e} \cdot\left(H \cdot \gamma_{s}+S_{d} \cdot \cos \beta\right) \cdot(\sin \beta-\operatorname{tg} \delta \cdot \cos \beta) \cdot A_{1} \cdot A_{2} \cdot A_{3} \cdot A_{4} \cdot \gamma_{B} \cdot
$$

\section{Conclusion}

The research yielded the following conclusions: 
- for the protection of upper part of bank stabilization as hydrotechnic structure which is not affected by watercourse, it is necessary to use flexible reinforcements like grass seeding on a vegetated soil layer including a cubic geosynthetic mat as a reinforced element;

- there is no method for choosing geosynthetic material for slope reinforcement of hydrotechnic structure, that's why algorithm development is quite an important;

- the choice of geosynthetic material should be done taking into account the resistance of vegetated soil layer, forces that act upon the slope and changes of material properties in course of time and technological peculiarities of its placement.

\section{References}

1. A.A. Mikhasek, A.A. Smivalov, Scientific review 14, 102-109 (2015)

2. M.I. Balzannikov, A.A. Mikhasek, M.V. Rodionov, Scientific review 12, 471-475 (2014)

3. S.A. Pyavsky, M.V. Rodionov, I.S. Kholopov, MSAU Newsletter 6, 54-61 (2012)

4. M.I. Balzannikov, A.A. Mikhasek. Procedia Engineering 91, 183-187 (2014)

5. A.A. Mikhasek, M.V. Rodionov Procedia Engineering 91, 82-88 (2015)

6. Y.A. Senitsky, A.A. Mikhasek, A.V. Kozlov, Scientific review 23, 64-70 (2015)

7. V.A. Seliverstov, A.A. Orlova, Scientific review 3, 109-115 (2015).

8. RIMD Recommendations on geosynthetic material usage in road building and road reconstruction (2010).

9. EBGEO (Empfehlungen für den Entwurf und die Berechnung von Erdkörpern mit Bewehrungen aus Geokunststoffen) (2010) 